\title{
A Comparative Study of Maximum Voluntary Ventilation in Overweight \& Obese Adult Males
}

\author{
Divya Harsh ${ }^{1}$, Raghuveer Choudhary ${ }^{2}$ \\ ${ }^{1}$ Tutor, Department of Physiology, AIIMS, Rajkot, Gujarat, India, ${ }^{2}$ Sr. Professor \& Head of Department, \\ Department of Physiology, Dr. S.N. Medical College, Jodhpur, Rajasthan, India
}

\begin{abstract}
Introduction: Obesity is a global ep idemic. It is characterized by excessive fat accumulation in the body, which affects multiple organs including the respiratory system by various mechanisms. The Prevalence and severity of obesity in young adults is increasing worldwide. The lung functions can be measured by spirometry. The Maximum Voluntary Ventilation test evaluates the respiratory endurance and is influenced by the lung and chest compliance, control of breathing and airway resistance.
\end{abstract}

Aim: The purpose of this study was to compare the Maximum Voluntary Ventilation parameter in obese, overweight and non-obese adult males and to evaluate the impact of obesity on MVV.

Methodology: A cross-sectional study was conducted among seventy-six adult males of Western Rajasthan in the age group ranging 18-25 years were performed on a spirometer, who were further divided into three groups based on Body Mass Index (criteria for Asian Indians) two groups based on WHR (waist-hip ratio). The observed data were statistically analyzed using ANOVA, Post-Hoc test and Linear Regression test.

Results: In our study, we found a significant reduction in MVV values in overweight and obese. The obese males had MVV (L/Min) of $68 \pm 10.80$; overweight males of $78.77 \pm 17.93$ whereas corresponding values in non-obese were $112.61 \pm 19.42$. According to ANOVA, a highly-significant (HS) difference among the three groups $(\mathbf{p}<\mathbf{0 . 0 1})$. The multiple regression method reveals a negative correlation with MVV which is highly-significant $(\mathbf{p}<\mathbf{0 . 0 1})$.

Conclusion: Our study concluded that the impairment of Pulmonary Function is strongly associated with adult overweight and obese males. The reduction in BMI by reducing weight can reduce morbidity.

Keywords: MVV-Body Mass Index, Maximum Voluntary Ventilation, Pulmonary Function Tests, Spirometry.

\section{Introduction}

An increase in the prevalence of overweight and obese has been seen around the world. Obesity is a chronic disease characterized by excessive body fat that causes damage to the individual's health and is associated with comorbidities such as diabetes, hypertension and vascular dysfunction. Obesity may affect respiratory functions in a number of ways. In obese people, the presence of adipose tissue around the rib cage and abdomen and in the visceral cavity loads the chest wall and reduces pulmonary functions. Carbon- dioxide production increases as a result of increased body weight. Obese subjects consume approximately $25 \%$ more oxygen than non-obese subjects at rest. ${ }^{1}$

According to ICMR-INDIAB study 2015, prevalence rate of obesity and central obesity varies from $11.8 \%$ to $31.3 \%$ respectively. Obesity can cause deleterious effects on respiratory function such as alterations in respiratory mechanics, decrease in respiratory muscle strength and endurance, decrease in pulmonary gas exchange, lower control of breathing, limitations in pulmonary function tests and exercise capacity and impair health and quality 
of life. Obesity may affect several body functions and therefore, lead to higher morbidity and mortality rates in the population. The MVV test evaluates the respiratory endurance and is influenced by the respiratory muscle strength, the lung and chest compliance, and the control of breathing and airway resistance. In the case of obese individuals this variable is reduced mainly by mechanical injury to the respiratory muscles, caused by the excessive weight on the thorax. ${ }^{2}$

\section{Materials and Methods}

The present study is an observational cross-sectional study that is conducted to compare pulmonary function tests of non-obese with the overweight and obese. The study was carried out in the Department of Physiology, Dr. S. N. Medical College, Jodhpur with a sample size of seventy-six male subjects (adult males 18-45 years). Institutional ethical clearance was obtained before the commencement of the study. An informed consent was taken from each subject during the study. The subjects were first given an explanation about the purpose and procedure of the experiment.

\section{Inclusion Criteria}

- Males aged 18 to 45 years.

. Normal-weight with BMI 18.0-22.9 Kg/m².

- $\quad$ Overweight with BMI 23.0-24.9 Kg/m².

. $\quad$ Obese as a $\mathrm{BMI} \geq 25 \mathrm{Kg} / \mathrm{m}^{2}$.

\section{Exclusion Criteria}

- Smokers and tobacco chewers.

- Age below 18 years and above 45 years.

- The subjects with acute or chronic respiratory diseases, cardiovascular diseases and other major systemic illness.

\section{- People working in mining industry.}

Detailed history including name, age, Anthropometric parameters, resting cardiovascular parameters were taken.

\section{THE ANTHROPOMETRIC PARAMETERS}

The following Anthropometric Parameters were measured in all 76 subjects: -

- Weight was measured the nearest to $0.1 \mathrm{Kg}$ by weighing balance (Krup's Weighing Scale) after removal of shoes with light clothing only.

Height was measured to the nearest $0.5 \mathrm{~cm}$ against the wall without shoes using Stadiometer.

- Body Mass Index was calculated using Quetelet's equation. ${ }^{3}$

$\mathrm{BMI}=$ Weight $(\mathrm{Kg}) /$ Height $\left(\mathrm{m}^{2}\right)$

Table-1: BMI Criteria for Asian indians ${ }^{4}$

\begin{tabular}{|c|c|}
\hline B M I $\left(\mathbf{K g} / \mathbf{m}^{2}\right)$ & STATUS \\
\hline$<18.0$ & Under weight \\
\hline 18.0 to 22.9 & Normal weight \\
\hline 23 to 24.9 & Over weight \\
\hline$\geq 25$ and above & Obese \\
\hline
\end{tabular}

- Waist Hip Ratio (WHR) waist circumference was measured at the midpoint between the lower margin of the last palpable ribs and the top of the iliac crest, using a measuring tape $(\mathrm{cm})$. Hip circumference was measured around the widest portion of the buttocks with the measuring tape and the individual stands with closed feet, arms at the side and body weight evenly distributed, and should wear light clothes. And this measurement was taken at the end of normal respiration.

$$
\mathrm{WHR}=\frac{\mathrm{WC}(\mathrm{cm})}{\mathrm{HC}(\mathrm{cm})}
$$

Waist hip ratio for the males (Asian Indians) = $>0.90^{5}$

For Pulmonary Function tests electronic spirometer (Spiro Excel PC/Laptop based spirometer, Medicaid Systems). This instrument is capable of giving highly accurate and reliable test results. It consists of an ergonomic handset with a digital turbine transducer which was connected directly to a PC/Laptop's USB 
port. The test was carried out in a place convenient and comfortable for the subjects. Demonstration of tests were shown to subjects. The maximum voluntary ventilation (MVV) performed at least three times each, according to the standards of the American Thoracic Society with the subjects in the sitting position. Results were expressed as absolute values and as a percentage of the reference predicted values. The MVV was expressed in $\mathrm{L} / \mathrm{min}$. and as a percentage of the reference predicted values.

\section{Statistical Analysis}

Mean and standard deviation of maximum voluntary ventilation (MVV) of all the subjects were calculated by
Microsoft excel. The data was compared by One-way analysis of variance (ANOVA) in "Open Epi" software and Post Hoc test. The multiple regression analysis was performed by SSP software. The $\mathrm{p}<0.05$ was considered statistically significant.

\section{Results}

The average age, weight, height, BMI (body mass index) and WHR (waist hip ratio) of the subjects were as in Table -1. A total of seventy-six adult males were recruited and then classified on the basis of body mass index.

Table No.1: Mean Anthropometric Parameters

\begin{tabular}{|c|c|c|c|}
\hline Parameters & \multicolumn{2}{|c|}{ Mean \pm SD } \\
\hline & Control (N=33) & Overweight(N=11) & Obese (N=32) \\
\hline Age (Years) & $22.84 \pm 4.36$ & $23.36 \pm 2.90$ & $91.21 \pm 18.92$ \\
\hline Weight (Kg) & $65.03 \pm 3.84$ & $69.45 \pm 5.69$ & $169.98 \pm 15.27$ \\
\hline Height (cm) & $176.16 \pm 4.51$ & $165.09 \pm 12.6$ & $29.80 \pm 3.54$ \\
\hline BMI (Kg/m $)$ & $20.96 \pm 1.08$ & $23.8 \pm 0.51$ & $1.01 \pm 0.07$ \\
\hline
\end{tabular}

Table 2: Comparison of Maximum Voluntary Ventilation(L/min) between different BMI groups (ANOVA)

\begin{tabular}{|c|c|c|}
\hline BMI & $\begin{array}{c}\text { Maximum Voluntary Ventilation(L/ } \\
\text { min) (Mean } \pm \text { SD) }\end{array}$ & p-Value \\
\hline Normal & $112.61 \pm 19.42$ & $<0.01($ HS) \\
\hline Overweight & $78.77 \pm 17.93$ & $<$ \\
\hline
\end{tabular}

Note: -HS = highly significant 
Chart No.1: Comparison of Maximum Voluntary Ventilation(L/min) between different BMI groups (ANOVA)

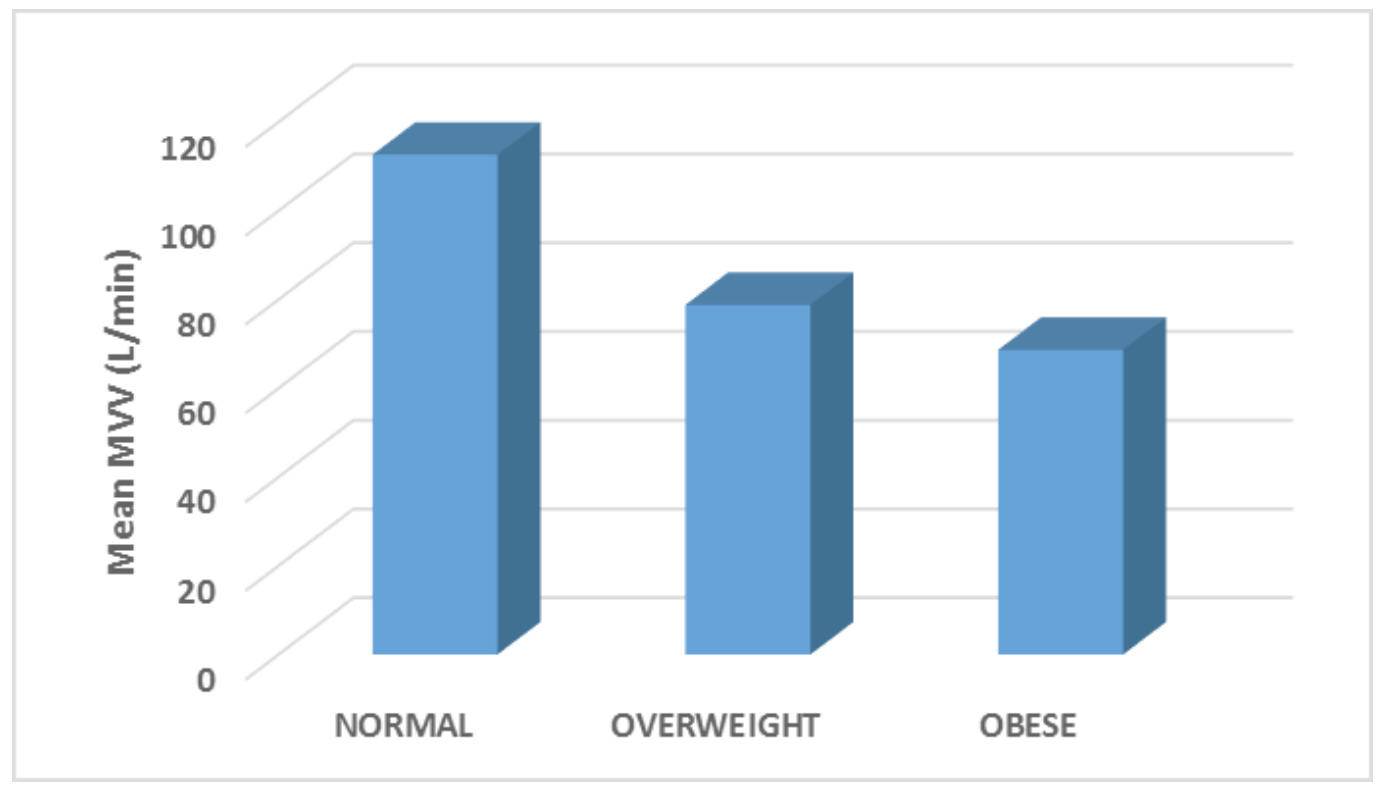

Table 2B: Comparison of Maximum Voluntary Ventilation $(\mathrm{L} / \mathrm{min})$ between different BMI groups (POSTHOC TEST)

\begin{tabular}{|c|c|}
\hline BMI & p-Value \\
\hline Normal v/s Overweight & $<0.01(\mathrm{HS})$ \\
\hline Normal v/s Obese & $<0.01(\mathrm{HS})$ \\
\hline Overweight v/s Obese & $>0.05(\mathrm{NS})$ \\
\hline
\end{tabular}

Note: $-\mathrm{HS}=$ highly significant, NS = non-significant

Table 2, 2B \& Chart 1 shows MVV values among different BMI groups. The one-way ANOVA demonstrated a statistically highly significant difference $(\mathrm{P}<0.01)$.

Table No. 3: Correlation of Obesity and Waist-To-Hip Ratio with MVV-

\begin{tabular}{|c|c|c|}
\hline PFT Parameters & BMI & WHR \\
\hline MVV & $\mathbf{- 0 . 6 4 5}^{\text {** }}$ & $\mathbf{- 0 . 5 3 2}^{* * *}$ \\
\hline$\% \mathrm{MVV}$ & $\mathbf{- 0 . 5 4 9}^{* *}$ & $\mathbf{- 0 . 4 2 5 ^ { * * }}$ \\
\hline
\end{tabular}

Note: $-^{* *}=p<0.01$ (Highly Significant), ${ }^{*}=p<0.05$ (Significant)

Table no. 3 is showing a correlation between MVV and obesity indices (BMI \& WHR). Therefore, MVV is strongly correlated with obesity. 
Table No. 4: Multiple Regression Analysis of Obesity and Waist-To-Hip Ratio with MVV-

\begin{tabular}{|c|c|c|c|c|}
\hline \multirow{2}{*}{ PFT Parameter } & \multicolumn{2}{|c|}{ BMI } & \multicolumn{2}{c|}{ WHR } \\
\hline & Coefficient & p-value & Coefficient & p-value \\
\hline MVV & -0.05 & $0.00^{* *}$ & -0.00 & $0.02^{* *}$ \\
\hline
\end{tabular}

Note: $-^{* *}=p<0.01$ (Highly Significant)

In the table no. 4, the multiple regression method was applied to find the effect of BMI and WHR on maximum voluntary ventilation. It shows that BMI is negatively correlated with MVV and this relation is found to be highly significant $(\mathrm{p}<0.01)$.

Chart No.2: Linear Regression (MVV dependent variable)-

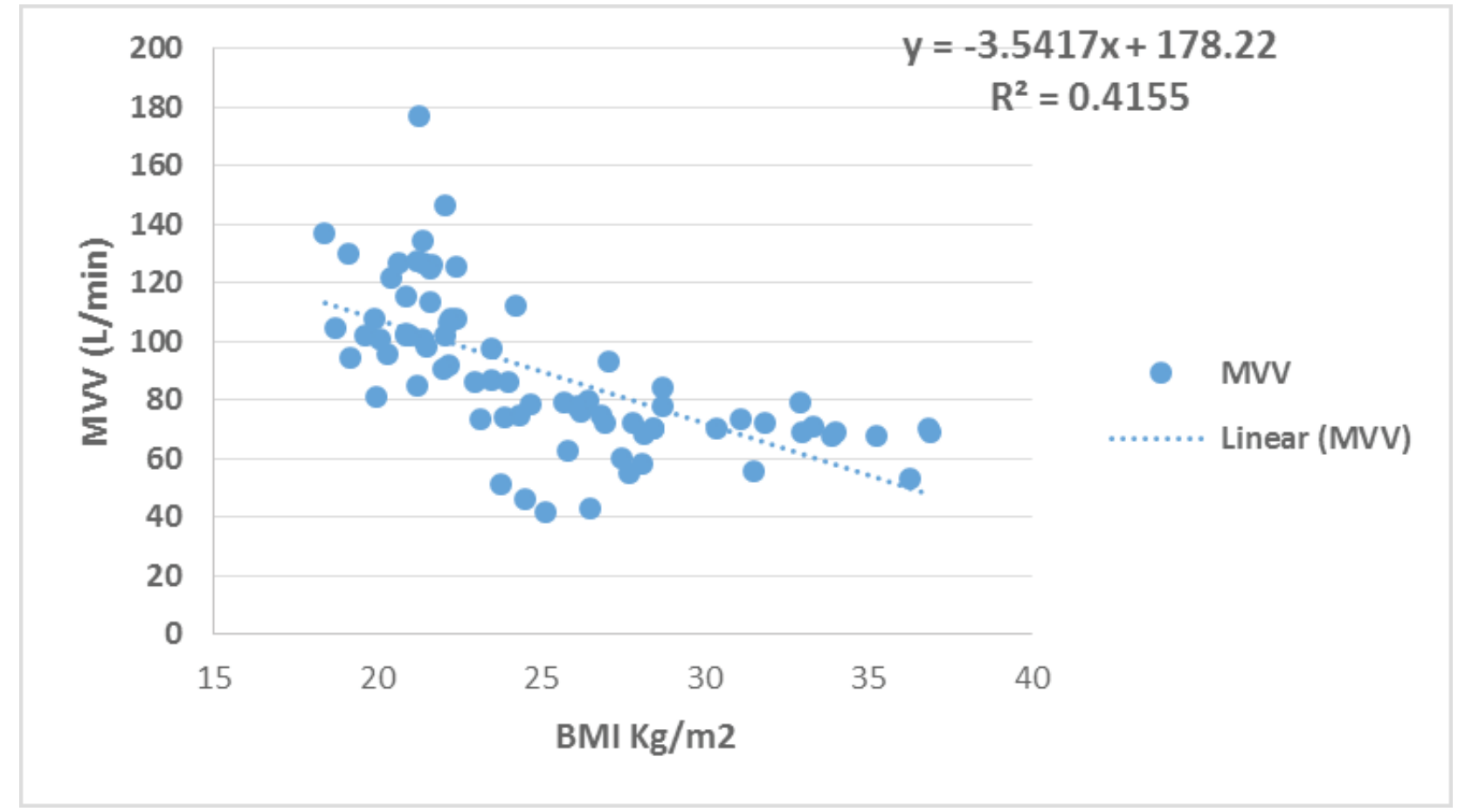

Coefficient of determination $(\mathrm{R}$ squared $)=0.4155$

The standard error of estimate $=178.22$

Graph implies that the BMI is negatively correlated with maximum voluntary ventilation and this relation is found to be significant. 
Chart No.3: Linear Regression (MVV dependent variable)-

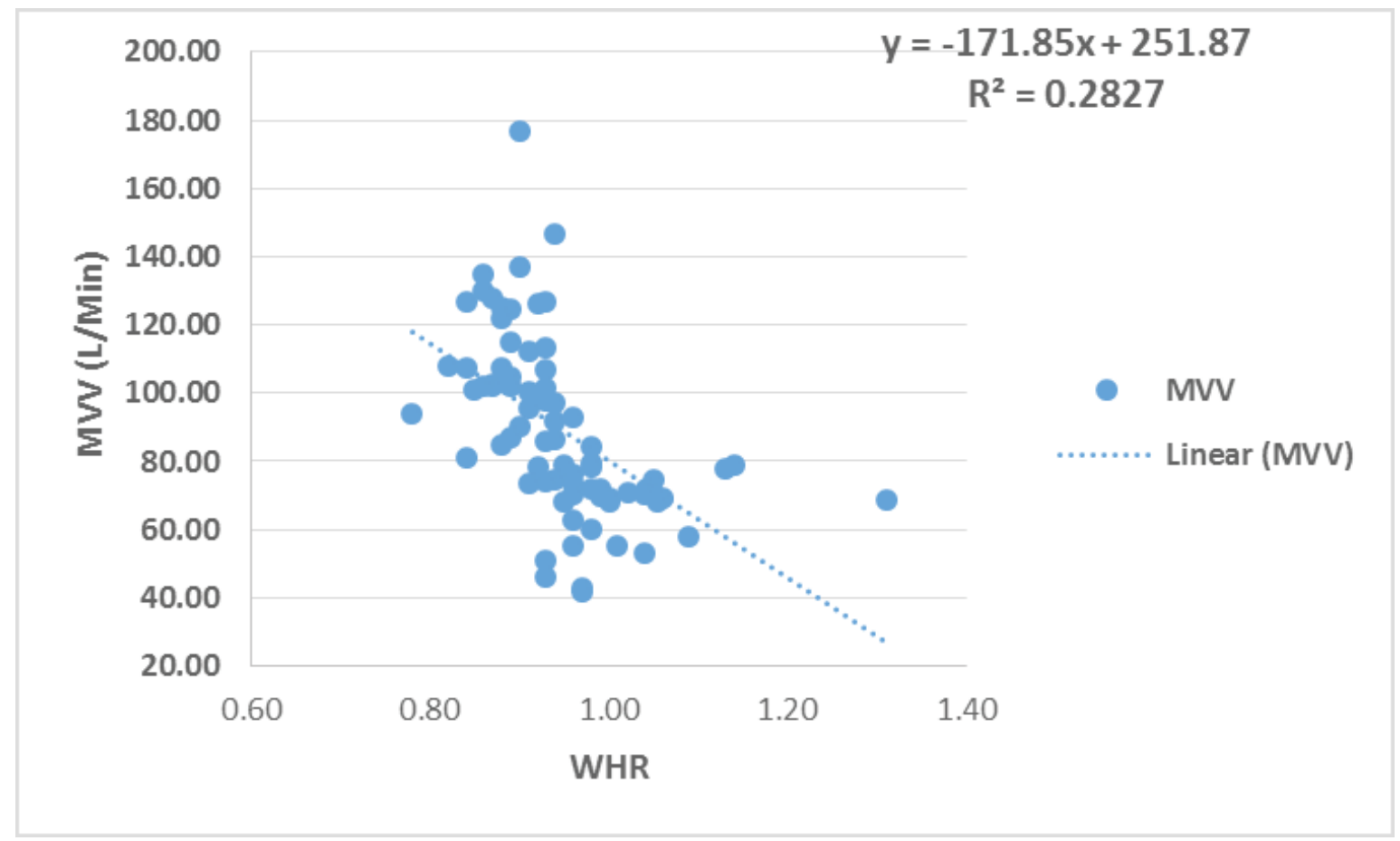

Coefficient of determination $(\mathrm{R}$ squared $)=0.2827$

The standard error of estimate $=251.87$

Graph implies that the WHR is negatively correlated with maximum voluntary ventilation and this relation was found to be significant. Reduction in MVV in obesity is due to a direct mechanical effect on the distribution of body fat. ${ }^{8}$

\section{Discussion}

The prevalence and severity of obesity in adult males are dramatically increasing worldwide. ${ }^{6}$ Among the harmful effects of obesity to health, the respiratory changes represent an additional factor with functional limitation and detriment to the quality of life of obese individuals. A significant finding of the study is decrease in the MVV in the overweight and obese group. The MVV test evaluates the respiratory endurance and is influenced by the respiratory muscle strength, the lung and chest compliance, and the control of breathing and airway resistance. ${ }^{9}$ It provides an overall assessment of the effort, coordination, and flow-resistive properties of the respiratory system. Similar results were obtained in the studies done by various authors as shown in table no. 5 - 
Table No.5: Comparison of present study with other studies

\begin{tabular}{|c|c|c|c|c|}
\hline \multirow{3}{*}{$\begin{array}{c}\text { Studies } \\
\downarrow\end{array}$} & \multicolumn{3}{|c|}{ Maximum Voluntary Ventilation (L/min) } & \multirow{3}{*}{ p-value } \\
\hline & \multicolumn{3}{|c|}{ BMI $($ Mean \pm SD $)$} & \\
\hline & Normal & Overweight & Obese & \\
\hline $\begin{array}{l}\text { Present study } \\
\text { (2019) }\end{array}$ & $112.61 \pm 19.42$ & $78.77 \pm 17.93$ & $68.85 \pm 10.80$ & $<0.01$ \\
\hline $\begin{array}{l}\text { Oona Mandal et al } \\
\qquad(2018)\end{array}$ & $114.29 \pm 16.75$ & $98.44 \pm 14.77$ & $98.97 \pm 12.73$ & $<0.01$ \\
\hline Shah Bijal (2017) & $80.89 \pm 10.52$ & - & $86.90 \pm 9.84$ & $<0.05$ \\
\hline Ashwin Sorani et al & $121 \pm 32.16$ & $117.8 \pm 8.6$ & - & $>0.05$ \\
\hline $\begin{array}{l}\text { Paralikar et al } \\
\qquad(2012)\end{array}$ & $148.96 \pm 29.04$ & - & $108.45 \pm 22.6$ & $<0.01$ \\
\hline Costa et al (2008) & $122.60 \pm 19.80$ & - & $108.50 \pm 3.30$ & $<0.01$ \\
\hline Joshi et al (2008) & $126.23 \pm 24.08$ & $115.30 \pm 19.11$ & - & $<0.05$ \\
\hline
\end{tabular}

The MVV values for Normal weight, Overweight and Obese are 112.61 $\pm 19.42,78.77 \pm 17.93,68.85 \pm 10.80$ respectively.

On comparing the Normal, Overweight and Obese group, we found that there was a significant reduction in MVV with increasing BMI and statistically it comes out to be highly-significant $(\mathbf{p}<\mathbf{0 . 0 1})$.

In the present study, MVV was highest in normal weight and lowest in obese which is a result of air trapping that is inspiratory muscles are placed at a mechanical disadvantage which leads to lower inspiratory pressure and flows, and reduced respiratory muscle strength, causing a low MVV. Alternatively, in some obese patients, diaphragmatic muscle weakness is due to excessive weight on the thorax which causes a decreased MVV. Also, this may reflect extrinsic mechanical compression on the lung and the thorax. ${ }^{7}$

MVV was found to be an important contributor to obesity indices (BMI \&WHR) and was statistically significant $(\mathbf{p}<\mathbf{0 . 0 1})$. Similar results were observed by Oona Mandal et al (2018), Shah Bijal (2017) ${ }^{13}$, Ashwin Sorani .et al ${ }^{11}$, Paralikar et al (2012) ${ }^{10}$, Costa et al (2008), and Joshi et al $(2008)^{12}$.

Percentage of predicted Maximum Voluntary Ventilation 
Table No.6: Comparison of present study with other studies

\begin{tabular}{|c|c|c|c|c|}
\hline \multirow{2}{*}{\begin{tabular}{c}
\multirow{2}{*}{$\begin{array}{c}\text { Studies } \\
\downarrow\end{array}$} \\
\cline { 2 - 5 }
\end{tabular}} & \multicolumn{3}{|c|}{ \% MVV } & \multirow{2}{*}{ p-value } \\
\cline { 2 - 5 } & Normal & Ovi (Mean \pm SD) & \\
\hline Present study (2019) & $73.54 \pm 12.74$ & $53.56 \pm 12.13$ & $49.75 \pm 8.39$ & $<0.01$ \\
\hline $\begin{array}{c}\text { Shah Bijal et al } \\
(2017)\end{array}$ & $100.16 \pm 12.83$ & - & $112.40 \pm 112.40$ & $<0.05$ \\
\hline $\begin{array}{c}\text { Paralikar et al (2012) } \\
\text { Costa D et al (2008) }\end{array}$ & $131.53 \pm 0.00$ & - & $95.07 \pm 0.00$ & $<0.01$ \\
\hline
\end{tabular}

On comparing the Normal, Overweight and Obese groups, we found a significant reduction in \% MVV with increasing BMI which was statistically highly-significant $(\mathbf{p}<\mathbf{0 . 0 1})$.

In case of obese individuals, this variable is reduced mainly by mechanical injury to the respiratory muscles, caused by the excessive weight on the thorax. ${ }^{7}$

\section{Conclusion}

An observational study in young overweight and obese adult males showed that MVV values were significantly reduced. Hence, in this study, PFT parameter MVV showed statistically significant inverse relation with obesity. This indicates that obesity alters pulmonary functions which may give rise to long-term complications but these hazardous effects of obesity might be reversible and weight loss could improve lung functions.

\section{References}

1. El Solh AA, Jaafar W. A comparative study of the complications of surgical tracheostomy in morbidly obese critically-ill patients. Critical Care 2007; 11:R3.

2. Costa D, Barbalho MC, Miguel GP, Forti EM, Azevedo JL. The impact of obesity on pulmonary function in adult women. Clinics (Sao Paulo). 2008; 63(6): 719-24.

3. Canoy D, Luben R, Welch A, Bingham S, Warehiam $\mathrm{N}$, Day N. abdominal obesity and respiratory function in men and women in the EPIC-NorFolk study, Uk. American Journal of Epidemiology, 159(12), June2004, page 1140-1149.

4. World Health Organization. The Asia Pacific perspective redefining obesity and its textbook. $\mathrm{http} / / \mathrm{www}$.wpro.who.int/pdf/obesity final.pdf2000.

5. Waist Circumference and Waist Hip Ratio. Report of a WHO expert consultation. Geneva, Dec 2008.

6. Jung Eun Park, M.D., Jin Hong Chun, Kwan Ho Lee, Kyeong Cheol Shin, the effect of body composition on pulmonary function. TBRD. May 2012; Vol 72(5); page 433-440

7. Christopher Zammit, Helen Liddicoat, Ian Moonsie, Himender Makker. Obesity and respiratory diseases. IJGM 2010:3; 335-43.

8. Dr. Shah Bijal. Pulmonary function tests in obese and non-obese individuals. IRPMS. March 2017; 2(5); 43-50.

9. Malini M, Baljoshi VS, Kammar KF. A comparative study of impact of obesity on maximum voluntary ventilation in young adult women. Nalt J Physiol Pharmcol. 2017; 7(2); 174-177.

10. Swapnil J. Paralikar, Mukesh R. Dinkar. Abdominal obesity and pulmonary function in adults. IJBAP. 2012. Vol 1 (1). Page 205-206. 
16 International Journal of Physiology, July-September 2021, Vol. 9, No. 3

11. Ashwin Sorani, Chirag Savalia. Analysis of lung function in obese young adult males IJBAP. 2(11); 25-29.

12. Anuradha R Joshi, Ratan Singh and A R Joshi. Correlation of pulmonary function tests with body fat percentage in young individuals. IJPP. 2008. 52(4): 383-388.

13. Dr. Shah Bijal. Pulmonary function tests in obese and non-obese individuals. IRPMS. March 2017; 2(5); 43-50. 